\title{
Life-threatening angiocholitis following clot formation after balloon dilation for extraction of a large stone in the lower bile duct
}

Large-balloon dilation of sphincterotomy is used in the management of very large stones [1] as well as very small terminal bile ducts [1].

A 45-year-old man was seen for a symptomatic stone in the main bile duct. Endoscopic retrograde cholangiography (ERC) was carried out and an opacification confirmed the presence of a stone, $12 \mathrm{~mm}$ in diameter, just above the pancreas. The intrapancreatic bile duct was only $7 \mathrm{~mm}$ in diameter ( Fig. 1) and was dilated to $13 \mathrm{~mm}$ over a period of 1 minute by a CRE balloon (Boston Scientific, Nanterre Cedex, France) ( Fig.2). Extraction of the stone was uneventful, however, on the next day the patient developed moderate pancreatitis. On day 2 after stone extraction, the patient developed severe angiocholitis with Pseudomonas fluorescens septicemia. Antibiotic therapy was instituted immediately along with plastic stenting through a clot obstructing the lower main duct ( Fig.3), however, this did not prevent multisystemic failure accompanied by multiple liver abscesses. Complete recovery finally occurred after 1 month of hospitalization in an intensive care unit and a further month in a gastroenterology ward, with the antibiotic treatment continued throughout the period.

Balloon dilation of a narrow lower main bile duct after sphincterotomy for extraction of stones is a relatively novel [1] and useful technique. The method used in the present case was the same as has been reported previously [1]. It may be associated with severe and moderate bleeding [1], which may be delayed. In the present case, the ease of extraction excluded stone removal as being responsible for the bleeding. To the best of my knowledge, low grade bleeding leading to biliary obstruction after dilation has not yet been described. Large-balloon dilation after sphincterotomy is an exciting alternative to mechanical lithotripsy, as it is easy, quick, and efficient. Moreover, it allows delayed evacuation of calculi debris. It should, however, be kept in mind that the method is not without complications, which may be severe, and even fatal, but the risk cannot be predicted at present. Endoscopy_UCTN_Code_CPL_1AK_2AF

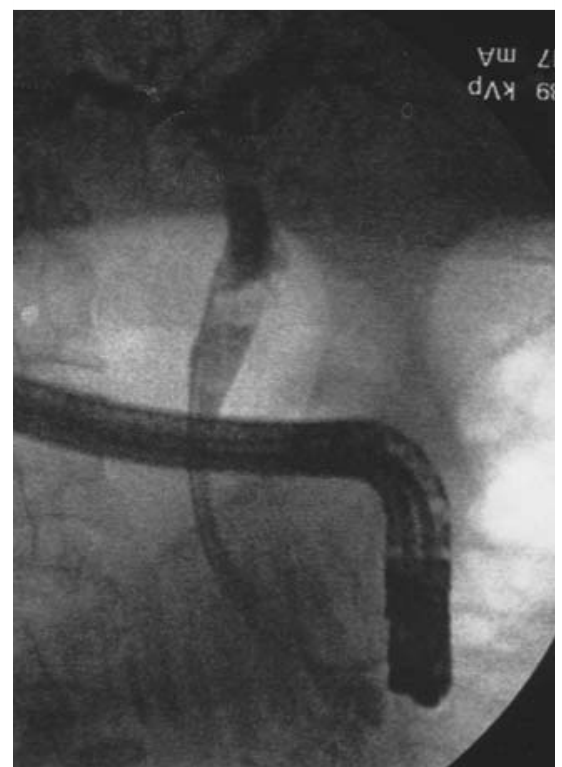

Fig. 1 Endoscopic retrograde cholangiography in a 45-year-old man with a symptomatic stone in the main bile duct: confirmation of stone and relative lower stenosis.
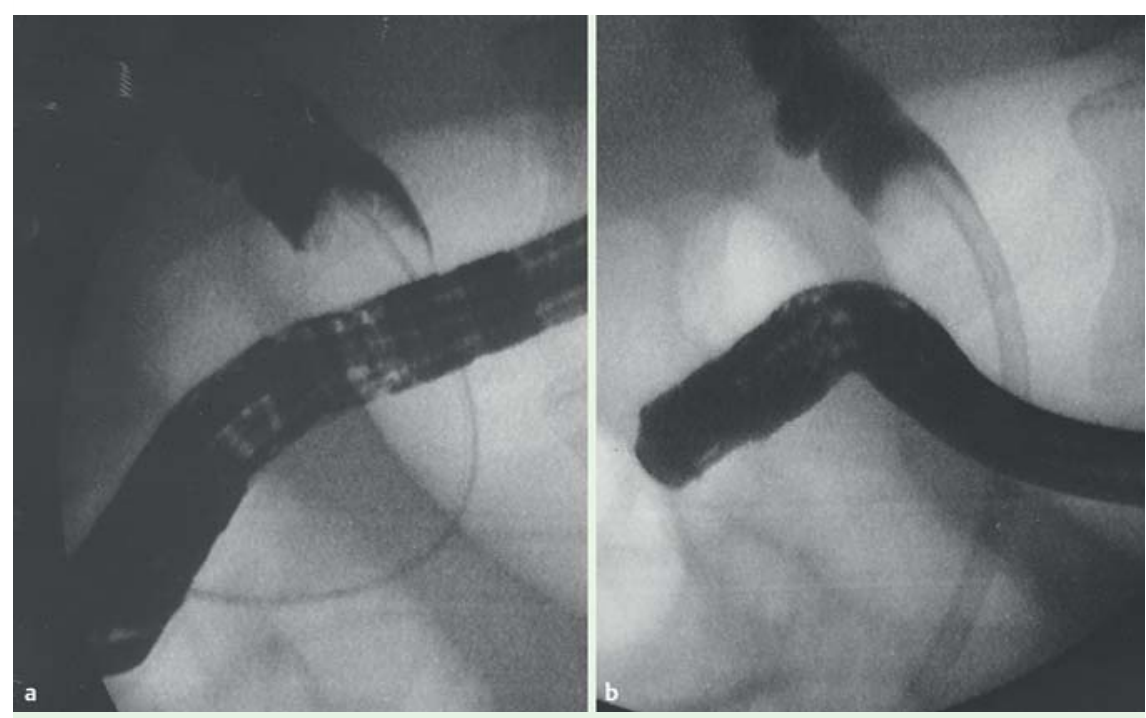

Fig. 3 a Clot obstructing the lower bile duct. b Plastic stenting through the clot. 


\section{Competing interests: None}

\section{B. Maroy}

Centre Clinical-Gastro BBMM, Soyaux, France

\section{Reference}

1 Maroy $B$. Life-threatening hemorrhage due to balloon dilation after sphincterotomy for extraction of a large stone. Endoscopy 2011; 43: E94-95

\section{Bibliography}

DOI http://dx.doi.org/

10.1055/s-0032-1326248

Endoscopy 2013; 45: E97-E98

(c) Georg Thieme Verlag KG

Stuttgart · New York

ISSN 0013-726X

Corresponding author

\section{B. Maroy}

Gastro BBMM

2 Chemin de Frégeneuil F

16800 Soyaux

France

Fax: +33-545-942500

bmaroy@yahoo.fr 